\title{
Robótica educativa livre no ensino de Física: da construção do robô à elaboração da proposta didática de orientação metacognitiva
}

\author{
Marco Antônio Sandini Trentin \\ Cleci Teresinha Werner da Rosa \\ Álvaro Becker da Rosa \\ Adriano Canabarro Teixeira
}

\section{Resumo}

O presente artigo compreende a descrição do processo de construção de um equipamento didático robotizado e a apresentação da proposta didáticometodológica para a abordagem dos conceitos introdutórios da cinemática no ensino médio. O dispositivo móvel robotizado foi projetado e construído utilizando materiais de baixo custo, de fácil aquisição e manutenção pelas escolas, sendo acompanhado por um programa de software livre denominado "Scratch". O estudo associa equipamentos tecnológicos de uso cotidiano com uma proposta didática estruturada para explicitar momentos de evocação do pensamento metacognitivo, ambos tidos como potencializadores da aprendizagem em Física. Este texto limita-se a descrever a construção do dispositivo e a apresentar sugestões de uso metodológico, remetendo a validação a outro artigo. Nesse sentido, são destacados, no presente estudo, aspectos concernentes à construção e à estruturação do dispositivo, bem como aos pressupostos teóricos da proposta didática. Como resultado, ao mostrar um dispositivo de fácil construção, o estudo evidencia que o uso de novas tecnologias no ensino está mais relacionado com a concepção epistemológica do professor do que com questões de natureza financeira. Em termos da proposta, o estudo revela a necessidade de que todo o produto educacional esteja vinculado a pressupostos teórico-metodológicos e, nesse contexto, ressalta o uso da metacognição como favorecedora da aprendizagem e seus benefícios enquanto mecanismo que possibilita o aprender a aprender.

Palavras-chave: ensino de Física; robótica educativa livre; metacognição.

\section{Abstract \\ Free educational robotics in physics teaching: from building the robot to creating a didactic proposal of metacognitive orientation}

The present article describes the process of building a robotic didactic device, and presents the methodological-didactic proposal to discuss the introductory concepts of kinematics in high school. The mobile robotic device was designed and built using low cost materials that were easy to find and be maintained by schools, and it came with a free software program named 
"scratch". The study associates technological equipment of everyday use with a didactic proposal structured to explain moments that recall metacognitive thinking, both considered enhancers of Physics learning. This text limits itself in describing the construction of the device and presenting suggestions of methodological use, validation is referred to another article. Thus, the present study highlights aspects concerning the building and structuring of the device, as well as the theoretical assumptions of the didactic proposal. As a result, by showing an easy-to-build device, the study proves that the use of new teaching technologies is more related to the epistemological conception of the teacher than to financial issues. Regarding the proposal, the study reveals the need for every educational product to be linked to theoretical and methodological assumptions, and in this context, it stresses the use of metacognition as a learning enhancer along with its benefits as a mechanism that allows learning to learn.

Keywords: Physics teaching; free educational robotics; metacognition.

\section{Introdução}

Dentre as principais preocupações dos educadores comprometidos com a melhoria da educação e com a transformação da sociedade, encontra-se a busca permanente pela (re)significação dos conteúdos escolares. A procura pela sintonia entre o que a escola ensina e o mundo vivencial dos estudantes tem sido a tônica dos debates proferidos nas comunidades científicas especializadas. Atualmente, entre os aspectos que ganham relevância nessas pesquisas, está a importância de alinhar o ensino com as tecnologias, especialmente com aquelas utilizadas pelos estudantes no seu cotidiano. O papel de mediador que esses novos recursos ocupam na sociedade contemporânea lhes confere o status de indispensáveis no sistema educacional, uma vez que esse sistema tem a função de preparar sujeitos para atuarem de forma crítica e consciente na sociedade, conforme apregoam os Parâmetros Curriculares Nacionais (BRASIL, 2002).

Contudo, a tecnologia, para ser incorporada ao sistema educacional, precisa ser dimensionada, não apenas em termos da criação de programas e softwares associados às disciplinas curriculares, como também em termos de estruturação de equipamentos tecnológicos apropriados para esse contexto. Especialmente, fala-se da escola pública, para a qual se julga imprescindível desenvolver e apresentar estudos com tecnologia economicamente viável. Tratase de ir além da utilização direta e única dos computadores, inserindo nesse contexto outros dispositivos tecnológicos, como os associados à robótica, por exemplo. Entretanto, tudo precisa apresentar custo acessível, possibilitando que os estudantes não apenas utilizem tais dispositivos, mas que aprendam, igualmente, a construí-los, montando-os e desmontando-os sem a preocupação com o custo da reposição de eventuais peças danificadas. E é nessa direção que emerge a Robótica Educativa Livre, considerada atualmente como uma das dez áreas em maior expansão no mundo, pois, além de contar com um hardware de baixo custo, também se apoia em softwares gratuitos e de fácil operacionalização.

R. B. E. C. T., vol 8, núm. 3, mai-ago.2015 ISSN - 1982-873X

DOI: Em andamento. 
Associada à importância da inserção da robótica na escola, destaca-se a pertinência de atrelá-la a propostas de uso metodológico fundamentadas em pressupostos teóricos que a justifiquem como recurso potencializador da aprendizagem, possibilitando ultrapassar a dimensão de que o estudante recebe conhecimento; afinal, ele precisa interagir com esse conhecimento, construindo-o a partir de seus saberes anteriores. Uma alternativa para isso são os referenciais construtivistas, com seus autores clássicos como Piaget, Ausubel, Vygotsky entre outros, que entendem o sujeito como construtor de seus saberes a partir de sua interação com o objeto do conhecimento.

Outra opção para além da estruturação construtivista, mas nela embebida, consiste na inserção de momentos de evocação do pensamento metacognitivo como forma de reconhecer permanentemente o que já se sabe sobre o objeto do conhecimento e, também, como possibilidade de que os estudantes exercitem o controle executivo para a realização de uma determinada ação. Ainda, a metacognição, enquanto estratégia de aprendizagem, possibilita que os estudantes aprendam a trabalhar em equipe e a refletir constantemente sobre seus conhecimentos, habilidades e compartilhamentos com o outro.

O exposto, em termos da importância de inserir na escola tecnologia a um custo acessível e atividades fundamentadas em propostas favoráveis à construção do conhecimento, do autoconhecimento e ao controle executivo, confere ao presente estudo o objetivo de desenvolver e validar uma proposta didática de orientação metacognitiva, que recorre ao uso de um dispositivo robotizado construído com materiais de baixo custo. Por limitações textuais, este artigo se ocupa de descrever o processo de construção do dispositivo robotizado a partir de materiais de baixo custo, com hardware e software livre; de refletir sobre o uso de tecnologias no sistema educacional; de discorrer sobre a importância do uso da metacognição como estratégia potencializadora da aprendizagem; e de apresentar duas propostas didático-metodológicas para o ensino dos conceitos iniciais da cinemática, na orientação metacognitiva. A aplicação da proposta no contexto educacional com a opção metodológica da pesquisa, seus resultados e discussões serão publicados posteriormente.

\section{Reflexões teóricas}

De acordo com Araujo e Veit (2004) desde a década de 1990, os computadores vêm sendo integrados ao ensino experimental de Física, principalmente em termos de coleta de dados e sua representação gráfica. Na época, os laboratórios virtuais iniciaram um tímido trabalho, apresentando-se como alternativa para ilustrar fenômenos ou mesmo para realização de exercícios de aplicação prática virtual. Atualmente, apesar de haver uma unanimidade sobre sua importância para o ensino, o uso de computadores ainda se apresenta distante da sala de aula, em especial na escola pública. As razões para isso são inúmeras, e uma delas é a falta de preparo 
dos docentes, somada à precariedade das redes de internet que chegam às escolas. Sem entrar nessa enseada, por fugir ao escopo do estudo, ressalta-se que esse distanciamento é ainda maior quando se trata de tecnologias que vão além dos computadores, como é o caso dos dispositivos robotizados. Essa tecnologia inteiramente presente no mundo vivencial dos estudantes tem passado longe de se tornar ferramenta didática do professor, especialmente no que se refere a dispositivos como tablets, smartphones ou mesmo sensores de tempo, de temperatura, etc. A situação é ainda pior quando se trata da robótica, que urge como alternativa para (re)significar o ensino de Física, por exemplo, considerada ciência básica para seu desenvolvimento.

Particularmente com relação à robótica, julga-se que sua presença como ferramenta educacional poderá atuar como auxiliadora do processo de ensino e de aprendizagem, na medida em que, mais do que um objeto atrativo e estimulante para os jovens, ela poderá representar uma gama de possibilidades de utilização estratégica no ensino de Física, além, é lógico, de permitir ilustrar e discutir fenômenos físicos no seu próprio funcionamento. Ensinar Física, por exemplo, limitando-se ao quadro branco ou aos livros didáticos é totalmente diferente de ensinar tendo ferramentas didáticas de natureza tecnológica, como são os robôs. Estudar aceleração, velocidade, lançamento, dilatação, entre outros conteúdos, utilizando um dispositivo eletrônico que permite manipular e criar possibilidades oportuniza ganhos cognitivos mais significativos que a exposição oral comumente presente nas aulas do ensino médio. Além disso, acredita-se que se estará agregando ao ensino conhecimentos tecnológicos que transcendem os conteúdos específicos e compartimentados da Física. Trata-se da possibilidade de um olhar para a empregabilidade da Física, além de ser um atrativo motivador da aprendizagem. Uma atividade experimental associada à ação de um robô poderá ofertar algo mais aos estudantes e distinto das tradicionais aulas de laboratório, especialmente aquelas associadas a roteiros rígidos como os "cooking book" (ROSA, 2011).

A utilização da robótica na sala de aula constitui-se em uma ação de inclusão digital, possibilitando que os estudantes visualizem na realidade escolar os eventos presentes no seu cotidiano. Além disso, pode oportunizar que os jovens saiam da escola com conhecimentos que Ihes sejam úteis para o mundo do trabalho e para sua formação enquanto sujeitos críticos e integrantes da sociedade contemporânea. Contudo, poucas são as instituições escolares no Brasil que a utilizam como instrumento para o processo de ensino e de aprendizagem, limitando sua utilização a competições com reduzido número de alunos. Conforme já destacado, é preciso que o professor tenha consciência de que a utilização da robótica como recurso didático-metodológico poderá contribuir para minimizar as dificuldades de aprendizagem dos estudantes e contribuir para qualificar a educação.

Outra característica da robótica é a possibilidade de trabalho em equipe, distribuindo tarefas e organizando as ações. E, ainda, ao congregar a teoria à prática, ela é capaz de desenvolver nos alunos conceitos e posturas que as demais atividades escolares dificilmente 
abordam, quais sejam: trabalho em equipe, autodesenvolvimento, capacidade de solucionar problemas, senso crítico, integração de disciplinas, exposição de pensamentos, criatividade, autonomia, responsabilidade, postura empreendedora, construção do pensamento lógico, imaginação, criatividade, entre outras. Lieberknecht (2009), a exemplo de outros autores como Castilhos (2006), Fabrício (2014) e Benitti (2012), mostra que a robótica estimula os alunos a buscarem soluções que integram conceitos e aplicações de outras disciplinas envolvidas, como matemática, física, mecânica, eletrônica, design e informática.

Em razão das vantagens do emprego da robótica na educação, salienta-se a possibilidade de sua utilização associada a propostas pedagógicas que tragam em seus princípios a valorização do autoconhecimento, do autocontrole e da regulação das ações. Tais elementos são identificados com a metacognição, remetendo ao pensamento metacognitivo, cuja evocação é apontada, no estudo de Chi e colaboradores $(1982,1989)$, como favorecedora da aprendizagem em Física. Além disso, esses autores atribuem a utilização dessa forma de pensamento como o diferencial entre os estudantes considerados experts em Física (com facilidade de aprendizagem) e os novatos (com dificuldades).

Nesse contexto e tendo como referencial os estudos de Rosa (2011), a metacognição é entendida como "o conhecimento que o sujeito tem sobre seu conhecimento e a capacidade de regulação dada aos processos executivos, somada ao controle e à orquestração desses mecanismos" (ROSA, 2011, p. 57, grifo da autora). Apoiada nos trabalhos de Flavell (1976), Flavell e Welmann (1977) e Brown (1978), a autora menciona que o conceito compreende dois componentes: o conhecimento do conhecimento e o controle executivo e autorregulador. Tal entendimento foi o adotado por Rosa (2011) para fundamentar propostas didáticas que buscam promover, nas aulas experimentais de Física, momentos de evocação do pensamento metacognitivo, cujos resultados apontaram sua viabilidade operacional e, ao mesmo tempo, possibilidades de ganhos cognitivos por parte do grupo de estudantes que utilizaram a referida proposta.

Ainda com base nos estudos mencionados anteriormente, entende-se que a metacognição é a tomada de consciência do sujeito sobre seus conhecimentos, seu modo de pensar, promovendo a regulação de suas ações. Quando associada a questões de natureza educacional, a metacognição é considerada uma estratégia de aprendizagem, possibilitando que os estudantes executem ações a partir da identificação de seus conhecimentos. A potencialidade para a aprendizagem dessa forma de pensamento reside no fato de promover nos estudantes uma identificação de seus saberes, oferecendo-Ihes condições de controlar a execução de suas ações como se um supervisor monitorasse seus pensamentos. Dessa forma, ao refletirem sobre seus próprios pensamentos e ações, os estudantes tornam-se capazes de controlar seus processos mentais e, assim, obter ganhos cognitivos. Em Física, isso leva à busca pelo conhecimento já 
existente na estrutura cognitiva, atuando como estímulo à construção dos novos conhecimentos (ROSA, 2011).

Além dos estudos citados, outros vêm mostrando os benefícios do uso da metacognição, como os desenvolvidos por Doly (1999), que destaca esse pensamento como algo benéfico para construir conhecimentos e competências com mais êxito e transferibilidade; para aprender estratégias de resolução de problemas que favoreçam o sucesso, a transferência e também a autorregulação; para que os estudantes tornem-se mais autônomos na gestão das tarefas e nas aprendizagens; e para desenvolver uma motivação para aprender e construir um autoconceito como aprendente.

Na defesa da utilização da metacognição em sala de aula, as pesquisas de Chi et al. (1989) e Bransford, Brown e Cocking (1999), por exemplo, apontam a necessidade de que sua inserção no processo educacional seja feita de maneira explícita, não deixando sob a responsabilidade do estudante a efetivação desse processo, porque poderá não ocorrer. Os autores são taxativos ao mencionar a necessidade de que esse pensamento seja ativado em sala de aula, com a inclusão de propostas didáticas voltadas à sua explicitação, especialmente em se tratando da aprendizagem em Física, cujo diferencial tem sido a utilização dessa forma de pensamento.

\section{Construção Do Robô}

Apesar das vantagens que apresenta, a inserção de recursos tecnológicos no processo de ensino e aprendizagem constitui um grande desafio para o Brasil na atualidade, pois a maioria das escolas não lhes tem acesso. Os kits de robótica de empresas comerciais, por exemplo, implicam um custo elevado para a realidade brasileira. Além disso, esses kits proprietários não possuem muita adaptabilidade no que diz respeito à interação com outros dispositivos que não pertençam ao fabricante ou escolhas de outras linguagens de programação não presentes no kit. Isso engessa a aplicabilidade do material em diferentes turmas e cria uma dependência tecnológica para com um fabricante (SANTOS; NASCIMENTO; BEZERRA, 2007). Dessa forma, urge desenvolver dispositivos de robótica a baixo custo para utilização nas escolas, especialmente a pública, não dependendo de verbas vultosas e morosas.

Devido ao sucesso e baixo custo do Arduino, plataforma em hardware livre para robótica educacional, a tecnologia começou a tomar grande impulso nos últimos anos, o que não quer dizer que seja recente. Já no início deste milênio, algumas escolas brasileiras já realizavam atividades de robótica educacional. Na época, elas se valiam de equipamentos obsoletos que eram descartados ou inutilizados, e deles eram retirados dispositivos eletromecânicos, como motores e sensores, além de outros materiais que poderiam ajudar o educando na montagem de seus projetos, tais como eixos, roldanas, engrenagens, fiações, bornes de ligação, resistores, transistores, reguladores de tensão, dentre outros (CÉSAR, 2005; CÉSAR; BONILLA, 2007). 
O Arduino possibilitou ampliar as formas de interação com os robôs criados em projetos de robótica. No caso de alunos da Educação Básica, por exemplo, não é esperado que eles interajam ou programem o robô através de comandos de linguagem de programação, por lhes ser algo ainda desconhecido e complexo. Nessas situações, existem softwares que "escondem" a complexidade da programação, apresentando aos alunos uma interface amigável, na qual, através de comandos de alto nível ou preenchimento de campos, ordens e parâmetros podem ser dados ao robô. Dentre eles se destaca o Scratch (2015), desenvolvido e mantido pelo Instituto de Tecnologias de Massachusetts (MIT), que visa auxiliar crianças a programarem computadores de forma visual, através de blocos de comandos e ações que são arrastados para uma área de trabalho. O Scratch, por meio de uma interface amigável e de alto nível, permite a criação de histórias animadas, jogos e outros programas interativos, podendo, inclusive, comandar um robô que faz uso da plataforma Arduino, através do uso da extensão S4A - Scratch for Arduino (BARBERO; DEMO; VASCHETTO, 2012). O S4A é uma modificação do Scratch que permite, de maneira facilitada, a programação do Arduino. Ele fornece novos blocos para o gerenciamento de sensores e atuadores ligados ao Arduino.

Com base nos parâmetros mencionados, o presente estudo ocupou-se de projetar e desenvolver um dispositivo robotizado com o objetivo de operar como equipamento didático para a abordagem dos conceitos introdutórios da cinemática em aulas de Física. Para tanto, o robô adquiriu o formato de um carrinho parametrizável composto por: um chassi de acrílico, podendo utilizado outro material semelhante, tais como chapas plásticas ou metálicas; um Arduino Uno; uma miniprotoboard, utilizado para permitir as conexões através de jumpers; seis LEDs, para serem utilizados como pisca-pisca, luz de freio e faróis; seis resistores sendo um para cada LED; um Buzzer, para ser utilizado como buzina; um sensor de luminosidade; dois seguidores de trilha; uma Ponte-H, para controlar os dois motores; dois motores com redução de 200:1; duas rodas plásticas, com revestimento de borracha para obter atrito; e, uma roda do tipo "roda boba".

Para poder comandar, ou obter dados, dos componentes listados acima, é necessário que os mesmos estejam conectados ao Arduino. No dispositivo utilizado neste projeto, os motores foram ligados a Ponte-H e esta ligada a 4 portas digitais do Arduino, uma vez que cada motor utiliza duas portas digitais. Também foram ligados nas portas digitais do Arduino os LEDs e o Buzzer. Já o sensor de luminosidade e os seguidores de trilha foram conectados as portas analógicas do Arduino. Para a fixação dos componentes ao chassi, foram utilizadas presilhas plásticas para fixar os motores, parafusos para fixar o Arduino e os Seguidores de Trilha, e cola quente para fixar os LEDs, a Ponte-H e a Roda "boba". O Buzzer e o Sensor de Luminosidade foram fixados diretamente na Miniprotoboard. Abaixo pode-se ver no esquema os componentes do carrinho. 


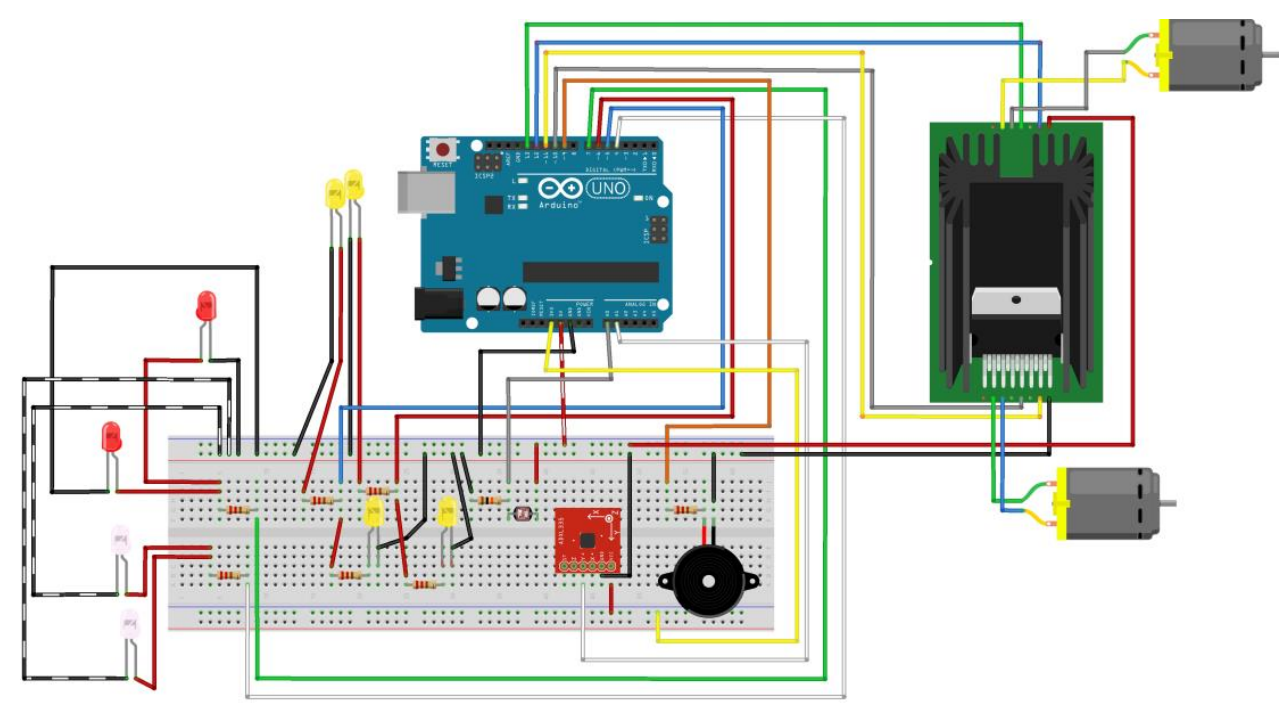

Figura 1: Esquema das conexões do carrinho.

(Fonte: arquivo dos autores, 2013)

Com a finalidade de testar os diversos componentes trabalhando em conjunto, realizou-se a montagem provisória e testes em um tempo de aproximadamente doze horas, o que permitiu avaliar os diversos componentes. A Figura a seguir ilustra o dispositivo denominado de "robô", construído no estudo, cuja proposta didático-metodológica será apresentada na continuidade.

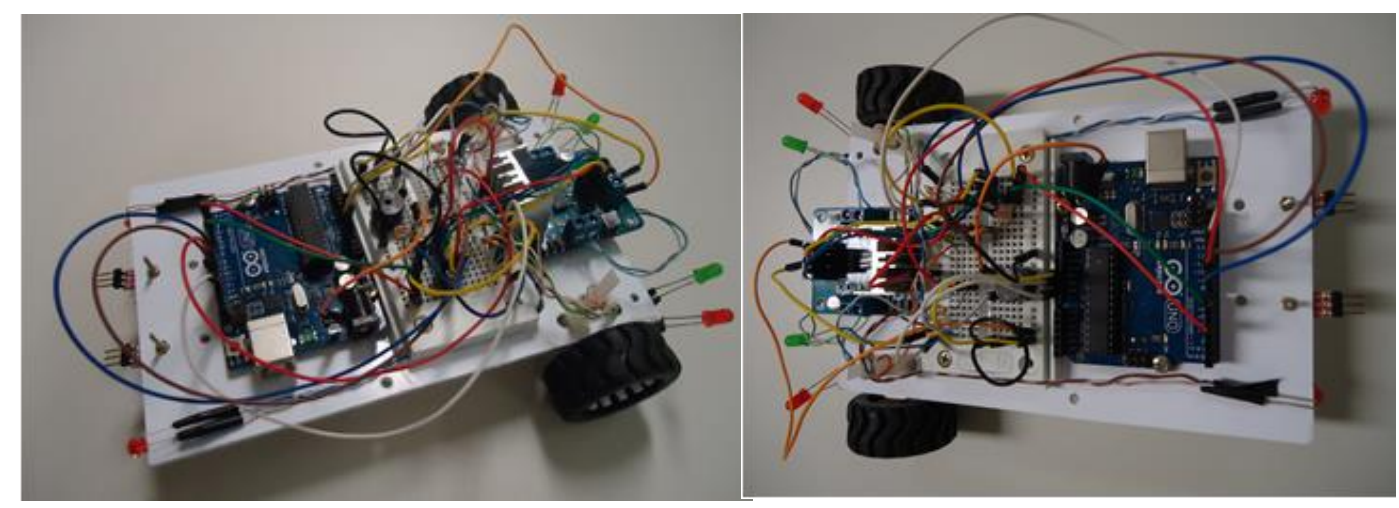

Figura 2: Carrinho parametrizável

(Fonte: arquivo dos autores, 2013)

Os materiais utilizados são facilmente encontrados no mercado e por preços bastante acessíveis, evidenciando que o processo de construção desse tipo de dispositivo básico é relativamente simples e de baixo custo. As placas Arduino, por exemplo, são de fácil aquisição e de baixo custo, comparadas às demais tecnologias existentes no mercado, e possuem uma série de portas digitais e analógicas que permitem comunicar-se com uma variedade de sensores, motores e outros componentes. 


\section{Proposta Didática}

A proposta a ser apresentada toma como referencial pedagógico a concepção construtivista dentro de uma orientação metacognitiva, considerando, entre outros aspectos, a importância de que, a cada tarefa, o estudante retome seus conhecimentos prévios, planificando suas ações de acordo com os objetivos pretendidos. A proposta de uso metodológico apoia-se no estudo desenvolvido por Rosa (2011) e leva em conta a necessidade de que os estudantes não apenas identifiquem seus recursos cognitivos e a relação que há entre eles como também planejem estratégias de ação, a fim de atingirem um determinado objetivo, procedendo a ajustes para que isso se concretize. Em outras palavras, propõe-se que o aluno reconheça em si e no seu grupo de trabalho quais os recursos cognitivos disponíveis e proceda à regulação da ação executiva.

Para tanto, estruturam-se duas atividades práticas destinadas ao estudo dos conceitos introdutórios da cinemática (deslocamento, trajetória e velocidade média), integrantes dos conteúdos de Mecânica, normalmente abordados no início do primeiro ano do ensino médio. Como equipamento didático, o estudo recorre ao uso do robô cuja construção foi descrita anteriormente, associando os conceitos físicos em estudo com parâmetros angulares e lineares. Tais parâmetros são digitados no computador pelos estudantes e informados ao robô. $O$ programa que orienta o movimento e as coordenadas desse dispositivo móvel é o S4A - Scratch for Arduino, que possibilita, mediante instruções mínimas, movimentar o carrinho em diferentes direções.

A seguir, descrevem-se as duas propostas de atividades práticas para aulas de Física, sendo uma para o estudo do deslocamento e trajetória e outra para o estudo da velocidade média.

\section{Proposta didática 1: Estudo da trajetória e do deslocamento}

A proposta inicial tem por objetivo estudar os conceitos de trajetória e deslocamento. Para tanto, propõe-se a construção de um circuito com obstáculos, o que pode ser feito no pátio da escola ou em outro lugar que comporte o movimento do robô, inclusive uma plataforma feita exclusivamente para esse fim. $O$ circuito, que será comum a todos os alunos, deve ser desenhado dentro de um quadrado delimitado por fitas do tipo crepe ou similares, com dimensões aproximadas de $5 \mathrm{~m} \times 5 \mathrm{~m}$. Nessa marcação, devem ser assinalados os pontos de saída e chegada do robô, preferencialmente em lados opostos do quadrado. No interior do quadrado, devem ser dispostos obstáculos construídos com caixas de papel do tipo caixa de sapato ou semelhante, tomando o cuidado de fixá-las com fita adesiva.

282 DOI: Em andamento.

R. Bras. de Ensino de C\&T 
Por ser a primeira atividade dessa natureza, julga-se importante que o professor defina previamente a posição dos obstáculos, levando em consideração que o carrinho deverá se deslocar em linha reta, podendo girar com ângulos que variam de grau em grau, dentro de um limite que vai de zero a $90^{\circ}$ no sentido horário ou anti-horário. O circuito deverá ter obstáculos, para que os estudantes não optem por seguir em linha reta até o ponto de chegada, e também deverá ter pontos de passagem obrigatória, instigando-os a tomarem decisões que envolvem situações mais complexas.

A Figura 3 ilustra um exemplo de circuito, mas é possível traçar e utilizar no estudo outras rotas com mais ou menos obstáculos. A situação ilustrada oportuniza aos estudantes trabalharem com ângulos e medidas lineares cujos parâmetros devem ser digitados no programa Scratch, que se comunica com o robô. Este, ao receber os comandos do computador, executa movimentos no circuito, sendo desafiado a deslocar-se do ponto de partida ao de chegada, sem limite de tempo.

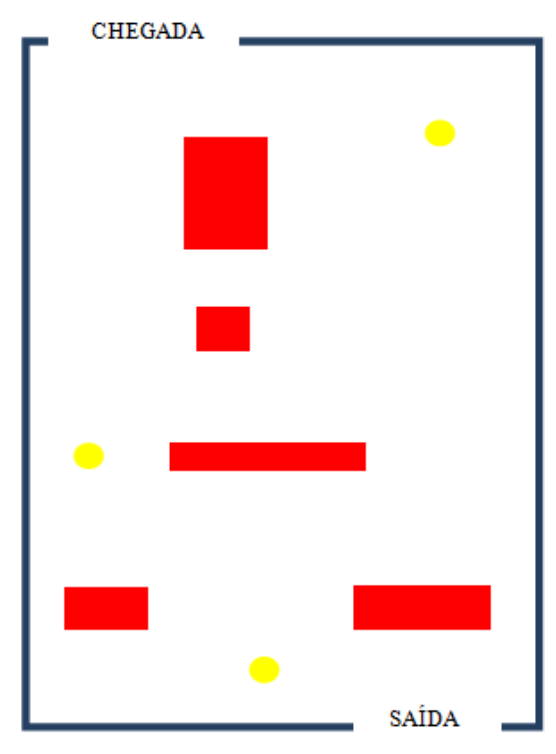

Figura 3: Pista para o estudo do deslocamento e da trajetória

(Fonte: arquivo dos autores, 2013)

A atividade inicia-se pela explanação do professor sobre o objetivo da atividade (levar o carrinho da posição inicial à final, sem tocar nos obstáculos e passando pelos pontos assinalados), procedendo-se, a seguir, à organização dos grupos de trabalho (sugere-se formar grupos de três a quatro estudantes). Nesse momento, é importante que os membros do grupo façam o reconhecimento de suas características pessoais e em comparação com os demais colegas que o compõem, a fim de que estabeleçam as equipes de trabalho considerando as habilidades e os conhecimentos de cada um.

Com os grupos estruturados, o objetivo apresentado e o material disposto, o professor deverá orientar os estudantes para que respondam, de forma oral, perguntas como: 
identifico o assunto com outro já estudado? Compreendi a atividade? Estou interessado em realizar a atividade? Apresento conhecimento sobre o assunto? Encontro-me em condições de realizar a atividade? Apresento limitações nesse tema? Essas perguntas podem ser entregues aos estudantes pelo professor, que, nesse caso, precisa atuar como instigador do pensamento metacognitivo inferido por tais questionamentos.

A partir desse reconhecimento, é importante possibilitar aos estudantes a identificação da tarefa e da estratégia por ela requerida, o que poderá ser feito com o auxílio de algumas questões, dentre as quais: entendi a tarefa? Que tipo de tarefa é essa? Identifico-a com outra já realizada? Julgo ter facilidade ou dificuldade em realizar tarefas como a proposta? Está de acordo com meus conhecimentos? Identifico o que é preciso para resolvê-la?

No que diz respeito à estratégia, sugere-se instigar os alunos para que respondam questionamentos metacognitivos, tais como: conheço estratégias para resolver este tipo de problema? Tenho facilidade com este tipo de estratégia? Qual a mais indicada? Há outras possibilidades de realização da tarefa?

$\mathrm{Na}$ continuidade, e por se tratar de uma primeira atividade dessa natureza, sugere-se que o professor apresente, no formato de planificação, ainda que oralmente, as ações que deverão ser executadas pelos estudantes. Dentre elas, está a necessidade de reprodução da pista em uma folha de papel quadriculado com os obstáculos e os pontos de passagem obrigatórios. Nesse momento, é necessário trabalhar com escalas, o que requer tempo para que os estudantes retomem seus conhecimentos anteriores sobre o assunto e consigam desenhar corretamente 0 circuito. Para essa reprodução, é preciso que cada grupo tenha em mãos um transferidor grande e uma fita métrica, a serem utilizados diretamente no circuito, e um transferidor e uma régua, para utilização no papel quadriculado.

Sem estarem competindo entre si, os estudantes deverão ser orientados a discutirem em seus grupos de trabalho sobre a melhor estratégia para levar o robô do ponto inicial ao final, planejando suas ações a partir da estratégia definida e compartilhada por todos na equipe. Inicialmente, os valores deverão ser verificados e desenhados no papel quadriculado, para somente após serem informados para o programa de computador, que orientará o carrinho. É importante que os estudantes percebam que, embora no papel os valores das medidas lineares sejam menores que no circuito, os ângulos são os mesmos lidos no circuito. Assim, se um grupo optar por fazer o carrinho andar dois centímetros e girar 30 graus haverá necessidade de transformação apenas do valor da medida linear. É imprescindível deixar que o próprio grupo chegue a essa conclusão, remetendo o papel do professor ao de mediador e supervisor das ações e das escolhas.

O professor deverá orientar os alunos que o computador poderá fornecer comandos ao carrinho apenas em duas situações: andar em linha reta tantos metros "para cima, 
para baixo, esquerda ou direita" e mudar a direção tantos graus "no sentido horário ou antihorário". Assim, os estudantes optam por alguns comandos que envolvem ângulos e outros que envolvem medidas lineares. Nessa atividade, os estudantes estão livres para optarem pelos caminhos que desejarem, desde que passem pelos pontos definidos inicialmente e não toquem nos obstáculos. O importante é sair do e chegar ao ponto determinado pelo professor (saída e chegada do circuito). O número de comandos é livre, e cada grupo faz suas opções, testando-as no circuito, a partir do que o grupo planejou. Como o circuito é único, os estudantes deverão ser organizados para que cada grupo faça seus testes. Isso, entretanto, deve ocorrer somente após o estudo do circuito desenhado no papel.

Durante o desenvolvimento da atividade, é importante que questões referentes à planificação e monitoração das atividades sejam respondidas pelos estudantes, mesmo que oralmente. Em termos da planificação, sugerem-se questões como: o que entendi sobre a atividade proposta? Identifico por onde devemos iniciar? Como organizar as informações apresentadas na atividade? Consigo visualizar o procedimento em relação ao fim almejado? E, em termos da monitoração, as questões sugeridas são: qual o sentido do que se está realizando? Qual o objetivo desta atividade? A estratégia que está sendo utilizada é adequada? O planejado está funcionando? Por que se está estudando este assunto? Por que estou realizando a atividade proposta? Continuando dessa forma, vamos atingir os objetivos dessa atividade?

Ao chegar ao final dessa primeira atividade, o professor poderá propor novas questões que auxiliem os estudantes na conclusão das tarefas em seus grupos de trabalho. Igualmente nesse processo, algumas questões poderão ser úteis, tais como: consigo descrever o que foi realizado? Qual era o objetivo proposto inicialmente? Qual o resultado da atividade? Os resultados encontrados foram os esperados?

Como conclusão, deve-se possibilitar que os estudantes procedam à escolha do título da atividade. No entender de Rosa (2011), além de atuar como um "pensar no que foi realizado", resultando na possibilidade de evocação metacognitiva, essa etapa representa uma excelente oportunidade para que o grupo retome as ações desenvolvidas e reconstrua seus caminhos. Assim, essa retomada constitui um importante processo cognitivo e que permite reconstruir saberes.

Ainda por conta do encerramento, ao professor compete oportunizar que os estudantes compartilhem com o grande grupo os resultados encontrados, o que corresponde a um significativo momento de reflexão sobre o procedimento e sobre o conhecimento adquirido com a atividade. Por meio da socialização dos saberes, os estudantes poderão constatar se entenderam a atividade e os respectivos resultados, razão pela qual esse é considerado um dos momentos mais significativos em um processo de construção de saberes, principalmente em atividades de natureza experimental. Habitualmente, o momento da conclusão da atividade é aquele em que os estudantes, já cansados, buscam respostas curtas, sem refletir sobre o 
realizado. Contudo, nesta proposta, atribui-se grande ênfase a essa etapa, por corresponder a uma oportunidade de rever o realizado em confronto com o que o outro realizou.

A atividade apresentada é uma das outras tantas possibilidades didáticas de organização do estudo. A seguir, apresenta-se uma segunda proposição, esta com ênfase no estudo da velocidade média e tendo em vista um processo didático que possibilita avançar no modelo anterior.

\section{Proposta didática 2: Estudo da velocidade média}

Para essa nova proposta didática, toma-se a mesma estrutura anterior, incluindo a variável tempo. Dessa forma, o circuito deve ser desenhado de modo que o dispositivo robotizado o percorra com a maior velocidade média possível. Isso implica que os estudantes procedam a escolhas mais refinadas e de maneira distinta da anterior. Em termos físicos, a velocidade média consiste na relação entre a distância percorrida e o tempo gasto para percorrer esse trajeto. Portanto, a maior velocidade média estará relacionada com a trajetória escolhida e com o tempo que o robô levará para percorrê-la. Contudo, vale lembrar que, para percorrer a trajetória, o robô gastará tempo cada vez que mudar de direção. Nesse contexto, os estudantes deverão, em seus grupos de trabalho, identificar que o número de paradas para mudança de direção, mesmo que isso signifique uma trajetória menor, poderá provocar um aumento no tempo de movimento e, consequentemente, diminuir a velocidade média. Por vezes, uma trajetória mais longa poderá representar um tempo de movimento menor, em virtude da menor quantidade de paradas para mudança de direção, resultando em uma velocidade média maior.

Para auxiliar nas decisões e na organização dos grupos, sugere-se que os questionamentos metacognitivos incluídos na proposta anterior sejam novamente considerados, por atuares como balizadores das escolhas e das ações adotadas pelos estudantes durante a atividade. Além disso, tais questionamentos permitem o reconhecimento de limitações pessoais e a autoavaliação dos conhecimentos adquiridos.

\section{Análise das propostas didáticas}

Como análise da proposta, destaca-se que, em termos cognitivos, o ganho esperado é o conhecimento, por parte dos estudantes, de como proceder na atividade e de quais os conhecimentos deverão ser recuperados na sua memória, principalmente em termos matemáticos (escalas, medidas lineares e ângulos). No caso específico da Física, busca-se a apropriação dos conhecimentos relacionados ao conceito de trajetória e deslocamento, na primeira atividade, e de velocidade média, na segunda. 
Na primeira atividade, é importante que o professor explore o conceito de trajetória, mostrando, ao final, que, para cada grupo, houve uma opção de caminho, o qual representa a trajetória percorrida pelo móvel. Fisicamente, trajetória não é sinônimo de deslocamento, pois este representa a diferença entre o ponto inicial e final sem envolver o caminho descrito pelo móvel. A medida desse caminho percorrido (trajetória) pelo carrinho, segundo a opção de cada grupo, pode ser calculada mediante os valores informados para o computador, podendo-se verificar a resposta no próprio circuito. Aqui estão sendo explorados conceitos matemáticos como as relações trigonométricas em um triângulo retângulo, cujo tópico é conteúdo do nono ano do ensino fundamental. Na segunda atividade, a ênfase ficou por conta do conceito de velocidade média.

Ambas as propostas buscam atuar como favorecedoras da evocação do pensamento metacognitivo, sendo esta evidenciada à medida que os estudantes forem levados pelo professor a desenvolverem suas ações e procederem a escolhas baseados na identificação de seu conhecimento acerca de seus próprios conhecimentos. Em outras palavras, a situação didática precisa atuar como instigadora da retomada, pelos estudantes, de seus conhecimentos no que se refere tanto às suas características pessoais quanto à tarefa e à estratégia a ser utilizada. De acordo com Flavell e Wellman (1977), pessoa, tarefa e estratégia são variáveis metacognitivas que resultam das crenças do indivíduo como ser cognitivo, representando o conhecimento que ele tem sobre si mesmo, o que afeta seu rendimento na realização de suas tarefas, inclusive as de aprendizagem.

Para Rosa (2011), tais variáveis manifestam-se na identificação, pelo estudante, de características pessoais, podendo estabelecê-las em comparação consigo próprio ou com o outro. No entender da autora, isso inclui os conhecimentos e as informações sobre determinados conteúdos, além da amplitude e da maneira como o estudante se relaciona com esses saberes. Trata-se de um feedback da estrutura interna de pensamento do sujeito, a qual poderá ser útil durante a realização de uma atividade em grupo, pois é no processo de interação que os estudantes balizam seus pensamentos e avaliam saberes, seja por comparação com o outro, seja pelos desafios da tarefa.

Ainda em termos metacognitivos, as atividades devem remeter, constantemente, os estudantes ao objetivo que as orienta, bem como à monitoração das ações frente a esses objetivos. Da mesma forma, ao final, é imprescindível que o professor retome a atividade realizada, estabelecendo relações e comparações entre os grupos, de modo a avaliar os caminhos percorridos por cada equipe, com vistas a verificar possíveis equívocos e desvios, sejam operacionais, sejam conceituais. Essa é, também, uma oportunidade para que professor verifique se os estudantes entenderam a atividade desenvolvida e o conhecimento envolvido. Monitoração e avaliação são considerados, ainda, elementos metacognitivos, de acordo com o estudo de Rosa (2011) apoiada em Brown $(1978,1987)$. Segundo esses estudos, o controle executivo de uma ação 
requer planificação, monitoração e avaliação, o que, em termos metacognitivos, significa a possibilidade de o estudante manter a atenção no objetivo proposto e de retomar constantemente suas escolhas e ações.

No que diz respeito à metacognição, a segunda proposta avança em relação à primeira, pois nela os estudantes necessitam proceder a escolhas e traçar estratégias frente a um objetivo desafiador e menos orientado pelo professor. Os estudantes procedem as suas escolhas de forma mais livre e devem traçar suas estratégias tendo como referencial o fim proposto. Nesse sentido, a tomada de consciência sobre o que sabem, sobre suas crenças em relação a si próprios e aos colegas e, também, sobre a tarefa que irão executar possibilita traçar estratégias com chances de lograr mais êxito ao final. O controle executivo e autorregulador intensifica-se nessa segunda atividade, uma vez que as opções dos estudantes precisam ser estabelecidas de acordo com o fim proposto, sendo necessário monitorar cada escolha.

A utilização de perguntas metacognitivas no decorrer das atividades é outra particularidade que contribui para que os estudantes percebam a necessidade de pensarem antes de agir e de manterem uma constante vigilância sobre suas ações. Os questionamentos metacognitivos buscam fornecer-Ihes elementos para que procedam as escolhas conscientes e de acordo com seus conhecimentos, no que se refere tanto a características pessoais como ao grupo, à atividade e aos conteúdos específicos em estudo.

A isso se pode relacionar as palavras de Giaconi, para quem

"Aquele que se observa, guia e avalia a si mesmo intelectualmente é aquele que pode organizar seus próprios processos de pensamento com eficácia, que pode dar um passo atrás mentalmente e deter-se a observar seu pensamento enquanto este se desenvolve, diagnosticando suas deficiências e identificando seus pontos fortes (2008, tradução nossa). "

Para que essa forma de pensamento seja adotada pelos estudantes, é preciso que as situações didáticas atuem como favorecedoras, permitindo-lhes exercitar a capacidade de estabelecer parâmetros que lhes permitam exercer um trabalho cada vez mais autônomo sobre o processo de desenvolvimento das tarefas. Planejar, controlar e avaliar o desenvolvimento das tarefas é uma alternativa para instituir essa forma de pensamento que vem se tornando um diferencial entre os estudantes que logram êxito em Física e os que apresentam dificuldade na sua compreensão.

Quanto à sua adoção no desenvolvimento da segunda atividade prática, destaca-se que o pensamento metacognitivo deverá estar vinculado à ação do estudante, servindo-lhe de referencial na estruturação de suas ações. 


\section{Considerações Finais}

O presente texto relatou o processo de construção de um robô didático a partir da utilização de materiais de baixo custo e disponíveis no mercado, apoiando-se em hardware e software livre. Além disso, apresentou sugestões de uso metodológico do dispositivo robotizado, por meio de duas propostas didáticas, para a abordagem dos conceitos iniciais da cinemática. Tais propostas foram construídas de modo a favorecerem a evocação do pensamento metacognitivo, atuando como potencializadora da aprendizagem, servindo de exemplo para novas atividades experimentais em Física.

Em termos do dispositivo robotizado, o estudo mostrou a viabilidade da sua construção a partir de materiais de fácil aquisição. Além disso, confirmou que sua utilização no contexto escolar está mais relacionada às concepções e aos conhecimentos dos professores, do que à disponibilidade de recursos advindos de apoios externos. $O$ trabalho demonstrou que é possível inserir tecnologia em sala de aula a custos baixos e que tais dispositivos podem se tornar instrumentos didáticos para os professores, aplicáveis também em outras atividades, e não somente naquelas dirigidas à robótica. Afinal, esta faz parte da aula de Física, não sendo uma disciplina ou atividade à parte.

Assim, acredita-se no potencial da robótica como uma possível estratégia permanente e abrangente de aprendizagem interdisciplinar, possibilitando a interação entre várias áreas do conhecimento e em vários níveis de ensino, dos anos iniciais à pós-graduação. A interdisciplinaridade precisa ser a tônica de um processo pedagógico que busca a formação de sujeitos preparados para atuarem de forma crítica e consciente na sociedade contemporânea. Contudo, é indispensável entender as dificuldades de um processo interdisciplinar inserido, por sua vez, em um processo formativo internamente disciplinar. Ou seja, como exigir dos professores uma atuação interdisciplinar quando sua formação ainda é compartimentalizada e disciplinar? Nesse sentido, supõe-se que o papel de estudos como o apresentado é o de provocar as discussões inerentes ao processo interdisciplinar, além de fornecer os subsídios necessários à sua efetivação em sala de aula.

No que concerne à proposta didática exposta no estudo, optou-se por fundamentá-la na perspectiva de que sua utilização no contexto educacional traga benefícios aos estudantes para além dos conhecimentos cognitivos, chegando ao desenvolvimento de competências que lhe assegurem continuar aprendendo. A respeito, destaca-se que a proposta foi concebida de modo que os estudantes, ao aprenderem um conceito, sejam capazes de transferi-lo a novas situações, assim como se tornem mais autônomos em seu processo de aprendizagem. Deseja-se ultrapassar a simples memorização dos conteúdos escolares, ou a sua aplicação às mesmas situações que originaram a sua aprendizagem, chegando à aplicação desses novos conhecimentos a diferentes e novas situações-problema. Conforme destacado por Rosa (2011), tal postura se refletirá na autonomia cognitiva dos estudantes, levando-os a adquirir conhecimentos suficientes para 
saberem como aprender e, assim, construírem seu modo de aprender para utilizá-lo por toda a vida.

Como continuidade deste artigo, será relatada, futuramente, a aplicação, na escola, da proposta didática. Também serão registrados e socializados a descrição metodológica da pesquisa, seus resultados e discussões. Por conta do projeto que sustenta o presente estudo, destaca-se que novos dispositivos robotizados estão sendo desenvolvidos, e, juntamente com eles, propostas e resultados de uso no contexto educacional deverão ser apresentados à comunidade.

\section{Referenciais Bibliográficos}

ARAUJO, I.S.; VEIT, E.A. Uma revisão da literatura sobre estudos relativos a tecnologias computacionais no ensino de física. Revista Brasileira de Pesquisa em Educação em Ciências, Belo Horizonte, v. 4, n. 3, p. 5-18, 2004.

BARBERO, A; DEMO, B.; VASCHETTO, F. A contribution to the discussion on informatics and robotics in secondary schools. $2012 . \quad$ Disponível em: <http://www.innoc.at/fileadmin/user_upload/_temp_/RiE/Proceedings/71.pdf>. Acesso em: 20 jul. 2013.

BENITTI, F. B. V. Exploring the educational potential of robotics in schools: A systematic review, Computers \& Education, Vol.58, pp. 978-988, 2012.

BRASIL, Secretaria de Educação Média e Tecnológica. PCN + Ensino Médio: orientações educacionais complementares aos Parâmetros Curriculares Nacionais. Ciências da Natureza, Matemática e suas Tecnologias. Brasília: Ministério da Educação, Secretária de Educação Básica, 2002.

BRANSFORD, John; BROWN, Ann L.; COCKING, Rodney R. How people learn: Brain, Mind, experience and school. Washington: National Academy Press for National Research Council, 1999.

BROWN, Ann L. Knowing when, where, and how to remember: a problem of metacognition. In: GLASER, Robert (Ed.). Advances in instructional psychology. Hillsdale, New Jersey: Lawrence Erlbaum Associates, 1978. v. 1. p. 77-165.

Metacognition, executive control, self-regulation, and other more mysterious mechanisms. In: WEINERT, Franz E.; KLUWE, Rainer H. (Eds.). Metacognition, motivation and understanding. Hillsdale, New Jersey: Lawrence Erlbaum Associates, 1987. p. 65-116. 
CASTILHO, M. Robótica na Educação: Com que objetivos?. Disponível em: < http://www.pucrs.br/eventos/desafio/mariaines.php\#conclusao>. Acesso em: 20 de jun. de 2015.

CÉSAR, D.; BONILLA, M. H. Robótica pedagógica com soluções tecnológicas livres no Cet CEFET em Itabirito - Minas Gerais - Brasil. In: CONGRESSO DA SBC, 27., 2007. Anais... Disponível em: <http://br-ie.org/pub/index.php/wie/article/download/953/939>. Acesso em: 6 jun. 2013.

CÉSAR, D. Robótica livre: robótica educacional com tecnologias livres. <http://libertas.pbh.gov.br/ danilo.cesar/robotica_livre/artigos/artigo_fisl_2005_pt_final.pdf.> Acesso em: 6 jun. 2013.

CHI, Michelene T.; GLASER, Robert; REES, Ernest. Expertise in problem solving. In: STERNBERG, Robert J. (Ed.). Advances in the psychology of human intelligence. Hilsdale, N.J.: Erlbaum, 1982. v. 1.

$\mathrm{CHI}$, Michelene et al. Self-explanations: How students study and use examples in learning to solve problems. Cognitive Science, v. 13, p. 145-182, 1989.

DOLY, Anne-Marie. Metacognição e mediação na escola. In: GRANGEAT, Michel (Coord). A metacognição, um apoio ao trabalho dos alunos. Tradução de Teresa Maria Estrela. Porto, Portugal: Porto Editora, 1999. p. 17-59.

FABRíCIO, P.R.A.M. Utilização da robótica na educação: um estudo de caso no município de Solânea. Trabalho de Conclusão de Curso. Graduação em Computação. Centro de Ciências Exatas e Sociais Aplicadas, Universidade Estadual da Paraíba, 2014.

FLAVELL, John Hurley. Metacognitive aspects of problem solving. In: RESNICK, Lauren B. (Ed.). The nature of intelligence. Hillsdale, New Jersey: Lawrence Erlbaum Associates, 1976. p. 231-236.

FLAVELL, John Hurley; WELLMAN, Henry M. Metamemory. In: KAIL, Robert V.; HAGEN, John W. (Eds.). Perspectives on the development of memory and cognition. Hillsdale, New Jersey: Lawrence Erlbaum Associates, 1977. p. 3-33.

GIACONI, Enriqueta. ¿Quésonlasguías de aprendizaje? Revista Electrónica Educrea, Santiago de Chile, n. 7. Disponível em: <http://www.educrea.cl/revista/html/ediciones/revista_10/03_dimensiones.php - 25k - 2008-0722>. Acesso em: 29 jul. 2008.

LIEBERKNECHT, E. A. Robótica educacional. 2009. Disponível em: <http://www.portalrobotica.com.br>. Acesso em: 30 jun. 2012. 
ROSA, Cleci T. Werner da. A metacognição e as atividades experimentais no ensino de Física. 2011. Tese (Doutorado em Educação Científica e Tecnológica) - Programa de Pós-Graduação em Educação Científica e Tecnológica, Universidade Federal de Santa Catarina, Florianópolis, 2011. . Metacognição no ensino de Física: da concepção à aplicação. Passo Fundo: UPF Editora, 2014.

SANTOS, F. L.; NASCIMENTO, F. M.; BEZERRA, R. Reduc: A robótica educacional como abordagem de baixo custo para o ensino de computação em cursos técnicos e tecnológicos. In: CONGRESSO DA SBC, 30., 2007. Disponível em: <http://www.br-ie.org/WIE2010/pdf/st06_02.pdf>. Acesso em: 30 jun. 2012.

SCRATCH. Disponível em: < https://scratch.mit.edu/>. Acesso em: 22 de jun. 2015.

Marco Antônio Sandini Trentin - Doutor em Informática na Educação pela Universidade Federal do Rio Grande do Sul (UFRGS). Docente do Curso de Ciência da Computação e dos Programas de Pós-Graduação em Ensino de Ciências e Matemática (PPGECM) e Computação Aplicada (PPGCA) na Universidade de Passo Fundo (UPF). E-mail: trentin@upf.br

Cleci Teresinha Werner da Rosa - Doutora em Educação Científica e Tecnológica pela Universidade Federal de Santa Catarina (UFSC). Docente do Curso de Física e dos Programas de Pós-Graduação em Ensino de Ciências e Matemática (PPGECM) e Educação (PPGEdu) na Universidade de Passo Fundo (UPF). E-mail: cwerner@upf.br

Álvaro Becker da Rosa- Doutorando em Educação Científica e Tecnológica na Universidade Federal de Santa Catarina (UFSC), Mestre em Ciências (Engenharia Biomédica) pelo Centro Federal de Educação Tecnológica do Paraná. Docente do Curso de Física e Engenharias na Universidade de Passo Fundo (UPF).E-mail: alvaro@upf.br

Adriano Canabarro Teixeira - Doutor em Informática na Educação pela Universidade Federal do Rio Grande do Sul (UFRGS). Docente do Curso de Ciência da Computação e dos Programas de PósGraduação em Ensino de Ciências e Matemática (PPGECM) e Educação (PPGEdu) na Universidade de Passo Fundo (UPF). E-mail: teixeira@upf.br 